\title{
Una epifanía nocturna: La niña de la lámpara azul. Estudio semiótico
}

\author{
SANTiago LópeZ Maguiña \\ Universidad Nacional Mayor de San Marcos
}

Para Adelita

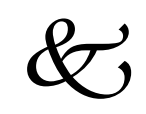

\begin{abstract}
Resumen
Este es un nuevo análisis semiótico de uno de los poemas canónicos de la literatura peruana: «La niña de la lámpara azul» de José María Eguren. Realizado con el empleo de categorías procedentes de la semiótica tensiva, el análisis destaca la polisensorialidad que ofrece la aparición luminosa que se despliega en el poema, que a la vez es una presencia femenina, conectada con significados de orden erótico, estético, fiduciario y mítico, principalmente. Se observa que el texto constituye un escenario en el que se realiza una puesta en escena cuyas significaciones se abren en un horizonte amplificante que el análisis apenas comienza a mostrar.
\end{abstract}

Palabras claves: La niña de la lámpara azul, Eguren, Semiótica tensiva, Polisensorialidad.

\begin{abstract}
An nocturn epiphany: La niña de la lámpara azul. A semiotic study

Taking on the semiotic perspective, the author works in a new interpretation of one the most importants poems of the peruvian poetry: La niña de la lámpara azul of José María Eguren. Using categories of the tensive semiotic, the author concludes that the poem shows a shaining figure, connected with erotics, estetics and mithics significants.
\end{abstract}

Key words: La niña de la lámpara azul, Eguren, Tensive semiotic, Polisensoriality. 


\section{Introducción}

«La niña de la lámpara azul» constituye uno de los poemas canónicos de la literatura peruana, que volvemos a visitar ${ }^{1}$ bajo los términos que nos ofrece la semiótica del discurso. He aquí el poema:

La niña de la lámpara azul

En el pasadizo nebuloso cual mágico sueño de Estambul, su perfil presenta destelloso la niña de la lámpara azul.

Ágil y risueña se insinúa, y su llama seductora brilla, tiembla en su cabello la garúa de la playa de la maravilla.

Con infantil y melodiosa con fresco aroma de abedul, habla de una vida milagrosa la niña de la lámpara azul.

Con cálidos ojos de dulzura y besos de amor matutino, me ofrece la bella criatura un mágico y celeste camino.

De encantación en un derroche, hiende leda, vaporoso tul; y me guía a través de la noche la niña de la lámpara azul.

La semiótica del discurso plantea que los acontecimientos discursivos, es decir, enunciados expuestos desde un cierto punto de vista, suponen un observador sensible respecto del cual se exponen. Al menos se distinguen por eso dos posiciones: la del observador sensible y la de los acontecimientos extendidos ante él, cuya presencia le suscitan cambios 
de estado de ánimo. A. J. Greimas con De la imperfección ${ }^{2}$, da una importante vuelta de timón en el desarrollo de su obra. Habiendo sistematizado una teoría semántica y narrativa fundada en recorridos narrativos previsibles y simétricos, se vuelca a estudiar textos en los que sobresalen apariciones súbitas. Pone en la mira eventos imprevisibles y deslumbrantes ${ }^{3}$ que provocan en el observador una radical variación afectiva. Así, «el ruido de la última gota [proveniente de una clepsidra ${ }^{4}$ ] cayendo en la fuente de cobre», que se revela cuando Robinson -el de Alain Tournier- es despertado por un «silencio insólito» ${ }^{5}$, permite la contemplación de un evento deslumbrante: «el detenimiento del tiempo marcado figurativamente por el silencio que bruscamente sucede al tiempo cotidiano, representado como un ruido ritmado». (1990: 31) Greimas subraya: a ese «silencio corresponde un detenimiento súbito de todo movimiento en el espacio, una inmovilización del objeto -mundo, del mundo de las cosas que hasta entonces no cesaban de 'inclinarse...en el sentido de su uso -y de su erosión- ...'». (1990: 31) La transición del tiempo marcado por el ruido ritmado, a la suspensión de la duración provoca entonces en quien lo contempla un cambio de ánimo. De un estado insensible (anestésico) pasa a un estado sensible (estésico). Experimenta un despertar afectivo ${ }^{6}$. Claude Zilberberg desarrolla toda una semiótica que pone énfasis en el análisis y la catálisis del evento, semánticamente marcado por lo imprevisto, y que, en consecuencia, se impone sobre un observador y hace de él un paciente, cuyo goce o mortificación son desencadenadas sin mediar la voluntad ${ }^{7}$. Cabe recordar que el Greimas de los años setenta y de los ochenta había desarrollado una semiótica de lo previsible, a través de sus modelos de gramática narrativa, que formaliza en términos de programas secuenciales de estados y de transformaciones predecibles. En la dirección de la semiótica del sobrevenir, que impresiona el universo sensible del observador y produce un trastorno afectivo, examinamos el poema de José María Eguren.

\section{Una aparición mágica}

La aparición de la niña de la lámpara azul no lleva la marca de lo que sobreviene. No constituye un «evento» en el sentido de «hecho 
imprevisto» que consigna el DRAE. Sin embargo la atmósfera en la que se hace presente «En el pasadizo nebuloso / cual mágico sueño de Estambul» se ofrece bajo el semblante de un mundo alterado, de otro mundo que no está caracterizado por una sucesión de acciones que se enlazan bajo el imperio de lo necesario y de lo posible, del deber ser y del no deber no ser, sino por eventos que llevan el signo de lo contingente, esto es, del no deber ser y de lo imposible, es decir, del deber no ser, relacionados con lo «mágico», con el «sueño», con «la vida milagrosa», que entrañan el contenido de lo inesperado.

Zilberberg en Semiótica tensiva sitúa al sobrevenir en el centro de la atención semiótica. El brillo es su principal expresión y se explica como una irrupción repentina constituida por una sensación móvil acelerada o veloz, y una intensidad tónica o acentuada, que determinan que su duración sea a menudo breve. Pero lo imprevisto en "La niña de la lámpara azul» aunque lleva rasgos de rapidez no tiene un carácter súbito. Su tonicidad afectiva en cambio es definitivamente fuerte. Los eventos que se suceden llevan el signo de una intensidad cada vez más fuerte. Su acaecer presenta una progresión tónica, cada vez más exaltada, hasta el punto en que su apogeo corresponde a una elevación que tiene un destino explosivo y «celeste» o celestial. El mundo maravilloso que se despliega está formado, en consecuencia, por una sucesión de eventos de una intensidad eufórica progresiva que, entre otras expresiones, presenta el desplazamiento de lo terrestre a lo celeste.

Pero no hay que dejarnos llevar en nuestra lectura por la fuerza de atracción que se desprende de la principal presencia desplegada en el horizonte perceptivo y sensible del poema, y hacer de ella la única energía motivadora. En el horizonte que se extiende ante el observador destaca en primer lugar «el pasadizo nebuloso», que hace pensar en «un mágico sueño de Estambul» y que despierta un ánimo de asombro. Un pasaje estrecho y "nebuloso», palabra ésta que el DRAE define así: "Que abunda en nieblas, o cubierto de ellas. 2. Oscurecido por las nubes. 3. Fig. Sombrío, tétrico, etc». Sin embargo, también uno es capaz de relacionar lo "nebuloso» con lo "vaporoso», que aparece en la última estrofa, y percibirlo como una presencia capaz de transfigurar las cosas. De ese modo la presencia de la neblina hace ver el "pasadizo» como «un mágico sueño de Estambul», que remite a un mundo exótico, 
determinado por una lógica distinta a la del mundo propio del observador. La aparición de este mundo es decisiva: a partir de allí todo cambia respecto del mundo previo que surge por contraste como el horizonte de los eventos cotidianos. Es el mundo de lo alumbrado ${ }^{8}$, que se asocia a la serie de acciones rutinarias constitutivas del mundo del día, pero también el de la noche seca y menos oscura, en oposición a la noche nebulosa y más oscura. Está implícito, por supuesto, el hecho de que en el horizonte figurativo del poema los eventos que en él tienen lugar se desarrollan en la noche.

\section{Lo rutinario y lo mágico}

Sin más detalle se pueden distinguir entonces dos horizontes: el horizonte de lo rutinario y el horizonte de lo mágico, diferenciados por la lógica de sus ocurrencias. El primero marcado por lo previsible, mientras que el segundo por lo imprevisible. Lo imprevisible sigue una lógica que Fontanille y Zilberberg, en distintos textos, llaman concesiva ${ }^{9}$, mientras que lo previsible sigue una lógica implicativa. La segunda es una lógica causal, del tipo "si...entonces». En el enunciado "Juan baila porque sabe y puede», el saber y el poder son la condición de que el actante realice la acción. El dominio de ciertas capacidades (relativas al saber y al poder) hace posible la efectuación de la operación. En el enunciado "Juan baila, aunque no sabe ni puede», en cambio, nos encontramos antes una situación en la que el actante, a pesar de no cumplir con las condiciones necesarias, realiza la acción. Un evento ocurre sin haber sido previsto, pronosticado o presentido. Esta regido por la concesión. La red siguiente resume en parte lo expuesto:

\begin{tabular}{|l|l|l|}
\hline & Mundo de lo rutinario & Mundo de lo mágico \\
\hline Figuras & Alumbrado, diurno, seco & $\begin{array}{l}\text { Nebuloso, nocturno, } \\
\text { húmedo }\end{array}$ \\
\hline Localización & Lo propio & Lo extraño \\
\hline Lógica & Implicación & Concesión \\
\hline
\end{tabular}


El otro mundo surge entonces gracias a una presencia atmosférica: la bruma que hace de las cosas presencia onírica, no sólo porque los sucesos responden a una lógica concesiva, sino porque permite que figuras y cualidades sensibles pertenecientes a ámbitos distantes y extraños entre sí se conecten y se condensen. De ese modo una presencia femenina, como la de la «niña de la lámpara azul» puede aparecer al mismo tiempo como una presencia natural (la combustión de un madero de abedul, o la lámpara) se identifique con la niña y ésta con aquella. Que en general una presencia humana se consustancie con una presencia luminosa o incandescente, formación que aparece también de manera similar en otros poemas de Eguren. La encontramos, por ejemplo, en «Las candelas» y en «Niñas de Luz».

\section{Una aparición inesperadamente esperada}

Es importante enfatizar que la aparición de la niña ocurre en una atmósfera que propicia realizaciones oníricas. Ello permite señalar que su ocurrencia no tome la intensidad fuerte de lo completamente inesperado, tonicidad vital difícil de precisar como dice Zilberberg. La aparición inesperada, en cambio, toma la condición de lo inesperadamente esperado, de lo sorprendente, cuya efectuación es deseable. El observador, en consecuencia, cuando la niña aparece no queda anonadado, perturbado, arrobado hasta la devastación. El observador queda intacto, es más, se despierta en él un ánimo sensible y un flujo de atención fuerte dirigido hacia la aparición. ¿No es ese el ánimo de la contemplación de quien siente la irradiación y emanaciones de lo maravilloso? La presencia lo envuelve y penetra, en una sola palabra lo invade de un modo que hasta podría llegar al pasmo. El observador del poema, sin embargo, no alcanza un punto de inmovilización debido a la presencia femenina. En cambio ella despierta una sensibilización en que se torna blanco de mira y hace de aquel fuente de captación, a partir de lo cual él así animado apunta a su vez hacia la fuente que lo sacude afectivamente: hace de la aparición de la niña blanco de atracción y de curiosidad, al tiempo que procede a ubicarla y cuantificarla en un horizonte visual, auditivo, olfativo, gustativo y táctil. 
Las irrupciones inesperadas de la atmósfera mágica tampoco presentan velocidades vertiginosas o fulminantes. Debemos precisar que la aparición de la «niña de la lámpara azul» se desarrolla como una serie de apariciones. Cada una de las facetas que va mostrando y que el observador mira y capta se presentan como presencias inesperadas y concesivas. No hay determinación de consecuencia entre la aparición de una faceta y otra. No existe entre ellas ninguna conexión de causa efecto. Pero a la vez ninguna de ellas aparece de un modo atropellado, en correspondencia con su velocidad rápida.

Primero el observador se sorprende y atiende a la presentación del "perfil... destelloso", que hace ver contornos luminosos formados por ráfagas intensas y de breve duración, tal como el DRAE define la palabra «destellar», cuya vivacidad está mitigada por el lexema "perfil». El destellar no parece proceder de la integridad del cuerpo, sino de su silueta. De la línea que lo delimita. Por otro lado, impresiona por su carácter difuso. El destellar es un "despedir», «arrojar» y mejor aun «irradiar»-que incluye la categoría figural de la dispersión- chispazos.

Enseguida la «llama...brilla». Tiene lugar entonces una transición luminosa, el paso de una presencia difusa a otra concentrada, pues la silueta luce ahora como un cuerpo integrado, que al mismo tiempo ofrece una tonalidad más viva, más intensa. Ese cambio visual resulta de un acercamiento: la presencia luminosa se aproxima al observador. Y se aproxima a una velocidad que no es ni rápida ni lenta. Es una velocidad moderada, que no anonada ni devasta, pero que maravilla o que asombra. De todas maneras se produce un movimiento que puede ser esquematizado de este modo:

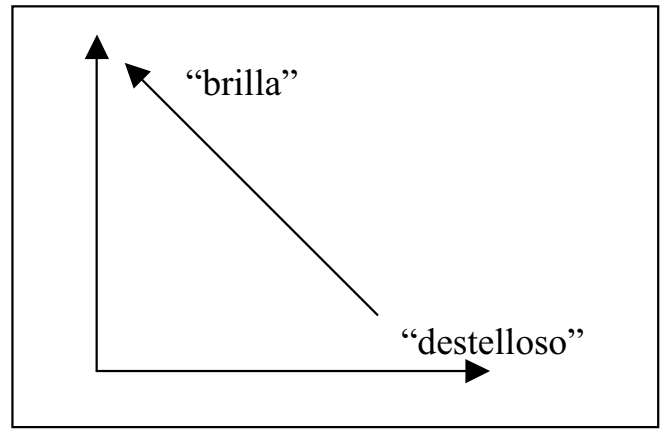


En este esquema tensivo, cuyo eje horizontal representa los grados de ocupación espacial de la presencia luminosa, y cuyo eje vertical representa los grados de intensidad tónica y de tempo que ella tiene, se da cuenta del desplazamiento que hemos descrito. La transición hacia una concentración e intensificación lumínica, que permite acentuar su nitidez y su fuerza alumbradora, y a la vez, a tono con el carácter sincrético de la aparición, revelar su rostro y sus pasiones humanas. "Ágil y risueña se insinúa, / y su llama seductora brilla». El movimiento «ágil», muestra un tempo ligero, importante también es señalar que según el DRAE es adjetivo que califica el poco peso y a la vez la rapidez pronta, veloz. A tenor de la argumentación que se viene desarrollando el acento de la mira recae por tanto sobre la densidad antes que sobre la velocidad. Y si bien la velocidad impresiona en el movimiento luminoso que acompaña la mayor intensificación del fuego (la "llama...brilla»), se trata de una velocidad aminorada, que produce un detenimiento móvil quizás similar al que se percibe en el picaflor que se suspende en el aire, con el muy agitado batir de sus pequeñas alas, tratando de chupar el néctar de la flor. La velocidad de la agitación es redoblada, pero la suspensión la aminora. Así surge la imagen de lo móvil detenido, movimiento que no irrumpe y avasalla, y en cambio se sitúa en el dominio de la espera y la fascinación ${ }^{10}$.

La agilidad del movimiento dependería de una velocidad situada en un intervalo cuyos grados sería interesante determinar entre los sinónimos que el diccionario de la computadora nos refiere. Una distribución posible en orden a su celeridad sería la siguiente: rapidez, prontitud, presteza, vivacidad, agilidad, ligereza, distribución que procede de una revisión del DRAE.

La agilidad correspondiente a un movimiento detenido se sitúa en el segmento de lo moderado, entre el exceso de velocidad (relacionado con las irrupciones bruscas) y el defecto de velocidad (relacionado con las apariciones calmas o estados de reposo). Conjuga con ese movimiento la expresión risueña del rostro humano, ubicada entre la risa y el silencio. Como lo «ágil», lo «risueño», es significante de grado intermedio, ni exclamativo ni mudo. Pero tónico, de intensidad fuerte, que mueve la carne en una dirección eufórica. La mirada egureniana, dicho sea de paso, se orienta definitivamente en un sentido distinto al 
de la mirada vanguardista que hace de lo inmoderado y excesivo valores positivos y tónicos.

La agilidad y la sonrisa de la aparición femenina se presentan enseguida asociadas a una actuación manipuladora, que revela una intencionalidad erótica ("se insinúa»), si nos atenemos a una de las acepciones de «insinuar» que proporciona el DRAE, «dar a entender aisladamente el deseo de relaciones amorosas». Mientras que su llama que brilla, cuando se enfatiza su faceta material, se siente "seductora», adjetivo que viene del sustantivo "seducir» que DRAE define así «Engañar con arte y maña, persuadir suavemente al mal. 2. Embargar o cautivar el ánimo", que Eguren está lejos de usar en un sentido perverso y que en cambio emplea en el sentido de cautivar, de atraer, de encantar, lo que se enfatiza en el primer verso de la última estrofa, y que de acuerdo al lenguaje natural tiene una carga erótica. La agilidad, la sonrisa, son signos de deseo amoroso dirigidos por la presencia femenina al observador y la llama que brilla es expresión definitiva del mismo deseo más acentuado.

\section{Asombro y fascinación}

Movimiento ágil, sonrisa, llama que brilla son figuras que integran la configuración de un estado de ánimo alegre, que se asocian a la vez con un intencionalidades eróticas, que hacen del observador blanco de mira, el cual fascinado y erotizado a su turno hace de la presencia femenina un blanco de mira que tendrá una progresiva acentuación. Sin aguzar mucho nuestra visión analítica percibimos además una variación tensiva entre las figuras de lo ágil y lo risueño vinculadas a la insinuación y la llama que brilla ligada a la seducción, que siguen a la sorpresa suscitada por el perfil destelloso y a la bruma que desata la transfiguración sensible que viene a continuación. Todo ello puede traducido al siguiente esquema: 


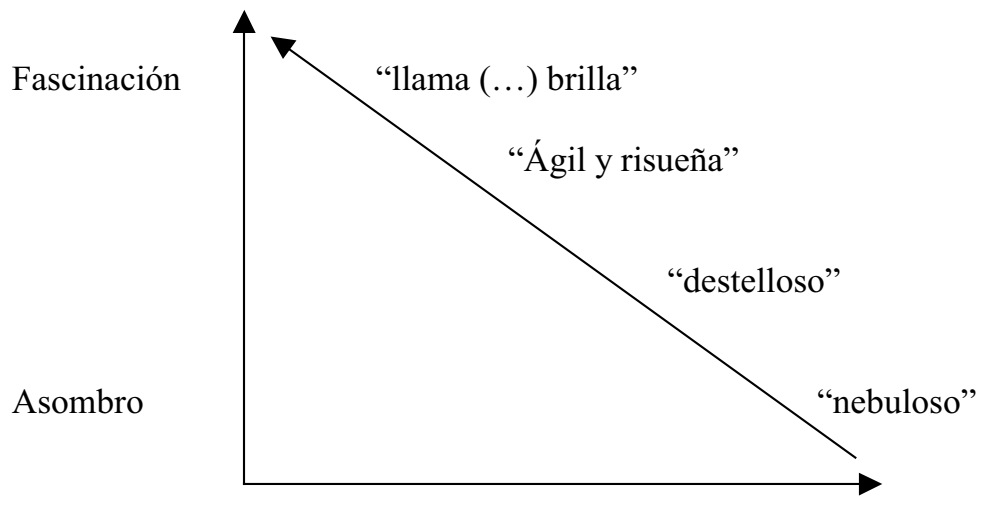

El asombro y la fascinación son sensaciones que pertenecen a la misma esfera o campo semántico. José Antonio Marina y Marisa López Peras los ubican en la familia de los sentimientos que resultan de la aparición del objeto ${ }^{11}$. Los autores estiman que «La primera aparición de un objeto en el horizonte del sentir, como una figura que se destaca sobre un fondo inerte de rutina o de irrelevancia, puede provocar distintas respuestas afectivas» (1990: 119). En general, la «novedad dispara los sistemas de alerta y sobresalto» (1990: 119) de los seres humanos, cuya actitud ante ella es ambigua: la desean y la temen. Desde un punto de vista pegado al sentido de las palabras cuyo sentido expresa sentimientos relacionados con la novedad, Marina y López Peras escriben que ellas refieren ante todo la puesta en alerta del organismo. "Le ponen sobre aviso, sin precisar aun si el recién llegado -estímulo, suceso, persona- es hostil o amistoso. La sorpresa, el susto, y el sobresalto darán colorido afectivo a ese primer aviso» (1990: 120). En este panorama «asombro» tiene un significado relacionado con el lexema «sorpresa». Se trata de una variante significativa de éste. El término sorpresa, tomado del francés, aparece en el siglo XVII dentro del campo militar. Para el Diccionario de autoridades es "Coger algo súbitamente y sin que lo espere el contrario, particularmente una plaza de armas. Úsase especialmente en la guerra». El mismo Diccionario añade: «vale también coger de repente alguna especie de ánimo, asustándole con la novedad o suspendiéndole». Contemporáneamente el término toma, sin embargo, la siguiente acepción: «Imprensión 
generalmente de alegría, produciendo a alguien haciendo una cosa que no espera», según María Moliner en su Diccionario de uso del Español (1990: 121). La palabra asombro, que elegimos para designar el estado de ánimo asociado con la atmósfera «nebulosa» y con el "perfil... destelloso» de la presencia femenina, tiene un significado oscilante, de acuerdo a Marina y López Peras, «Deriva de umbra y hace referencia al espantarse de las caballerías por la aparición de una sombra. Sin embargo, en la actualidad puede utilizarse también en sentido positivo» (1990: 122). Es la entrada de la sombra en el campo de presencia del observador lo que nos anima a elegir al asombro como estado de ánimo desatado por la aparición que ocurre en el poema estudiado, sombra que conjuga con la percepción transfiguradora del observador, que permite el surgimiento de apariciones fantasmales.

Con respecto al sentimiento de fascinación, los autores del Diccionario de los sentimientos, consignan la definición dada por María Moliner: "admirar, asombrar, atraer, cautivar, embelesar, encantar, pasmar». Y luego comentan que con respecto a otros sentimientos similares en los que el sujeto se limitaba a contemplar, en la fascinación es seducido, "sometido a encantamiento» (1990: 125). Encantamiento o encantación es lexema que aparece en el poema, y en su forma verbal significa según el DRAE: «Someter a poderes mágicos», «Atraer o ganar la voluntad de alguien por dones naturales, como la hermosura, la gracia, la simpatía o el talento», $\mathrm{y}$ «Entretener con razones aparentes y engañosas».

Entre el asombro y la fascinación o encantamiento en el poema que estudiamos se advierte pues no sólo una variación de intensidad afectiva, sino a la vez una mayor fuerza de atracción en la aproximación erótica que se desarrolla entre el observador y la presencia femenina luminosa.

A partir de las definiciones expuestas, estamos en condiciones de precisar la siguiente asociación semi-simbólica, que se puede plantear en términos de una relación causa-efecto considerando sólo la dimensión luminosa de la presencia femenina: cuando la luz del fuego se concentra y resalta en intensidad ella suscita en el observador la sensación de ser seducido, y en un nivel a la vez interno y externo -porque se siente en las envolturas y en los movimientos de la carne- provoca deseo ${ }^{12}$. 


\section{Certidumbre e incertidumbre}

El plano de significación figurativo formado por la oposición luminosidad / oscuridad se asocia, por otro lado, con el plano de significación conceptual y epistémico formado por la oposición certidumbre / incertidumbre. En efecto, el observador que desde el principio se presenta como un actor que se desplaza en medio de la noche, es alumbrado en primer lugar por la presencia femenina de la niña, más tarde invitado a seguirla por un camino "mágico» y "celeste», y, por fin, es guiado. La guía expresa sin duda una orientación, una dirección cierta, gracias a las luces, lo que por contraste ha de inferirse que la falta de guía expresa la ausencia de orientación debido a la oscuridad. De modo que es posible postular la siguiente proporción semi-simbólica:

Luminosidad : oscuridad : : certidumbre : incertidumbre

La certidumbre y la incertidumbre que son ante todo juicios epistémico sobre la adecuación o no adecuación entre lo nuevo y desconocido respecto de lo viejo y conocido ${ }^{13}$, se presentan en este poema como estados de ánimo relativos a la dirección o a la orientación que el sujeto tiene respecto al mundo en el que se mueve. En esa virtud hay que imaginar, siguiendo la hipótesis propuesta por Fontanille ${ }^{14}$ de que hay una correspondencia entre los estados de ánimo y los movimientos íntimos, los movimientos de la carne, una relajación corporal en el caso de la certidumbre, y una contracción en el caso de la incertidumbre. De ese modo tendremos un observador contraído somáticamente en medio de la oscuridad y relajado o distendido cuando es alumbrado por la presencia femenina.

Esa presencia ofrece así mismo al observador otras experiencias sensibles, ligadas tanto a su dimensión natural, como a su dimensión humana. En primer lugar, la percepción sonora que se experimentan también como eventos imprevistos y previstos: la «voz infantil y melodiosa» de la niña se oye con la misma sorpresa, pero también con la misma expectativa (esperanza) con que se ve iluminado y es ligeramente abrigado, pues las irradiaciones de luz también traducen calor. La voz, como toda cualidad sonora, rodea el cuerpo propio del sujeto y crea en torno a él una esfera independiente respecto al cuerpo 
perceptor, que se parece a la experiencia sensible del olfato. Como los olores que envuelven al cuerpo propio con capas olorosas de diversa extensión e intensidad, los sonidos lo encierran y lo pueden penetrar. Pero los sonidos se distinguen de los olores, en que pueden tocar y hasta herir la carne del sujeto ${ }^{15}$. En "La niña de la lámpara azul» se diría que la voz de la niña lo abraza deleitablemente y que así mismo lo penetra hasta tocar su carne con suavidad, de acuerdo con las cadencias melodiosas de su habla femenina. Estaríamos hablando entonces de una caricia. Como acabamos de hacerlo para el caso de la percepción de lo luminoso, imaginamos ahora que la carne, quizás contraída por el silencio reinante antes del contacto con la presencia sonora -sumado a la incertidumbre, el malestar de la falta de rumbo, la oscuridad-, se dilata o distiende al abrigo de la voz. Crece entonces la intensidad eufórica, al tiempo que disminuye la disfórica, pues el sentido, como lo anota Zilberberg, de acuerdo a Greimas, sigue siempre una dirección ambivalente ${ }^{16}$.

Lo mismo, la impresión de los aromas que la niña emana tendrían un efecto sorprendente. El "fresco aroma de abedul», que tiene un componente natural, el del abedul, árbol cuya madera produce fragancias ligeras y de fácil inhalación cuando es quemada, y que tiene así mismo un componente humano, correspondiente al olor corporal de la niña. Las cualidades sensibles que nacen de la combustión se hallan en sincretismo con las cualidades sensibles de la presencia femenina en el universo perceptible de este poema. En ese horizonte el olor suave del abedul es a la vez el olor suave de una infantil mujer. Esta es una presencia olfativa, como la voz, que rodea y penetra el cuerpo del observador hasta llegar a la carne, contribuyendo a relajarla sin que ello se haya esperado.

Después con el mismo efecto de asombro los ojos de la niña ofrecen una dulzura cálida. El lexema "dulzura» hace referencia ante todo a la calidad de lo dulce, que causa cierta sensación suave y agradable al paladar y que se opone a lo agrio o a lo salobre. Lo dulce, poco definido en el DRAE, es una cualidad gustativa importante: en el horizonte perceptivo del paladar constituye un evento sensible que no supone procesos de resistencia, de golpe o de herida. Su opuesto, lo agrio, supone en cambio resistencia y herida. Es a Claude Zilberberg a quien 
debemos la observación de que lo gustativo se relaciona con lo táctil. Lo dulce permite de ese modo el roce y la caricia, mientras que lo agrio comporta el golpe y hasta la herida (1999: 107-149).

¿Por el estado de extravío que vive el sujeto del poema no podría pensarse que siendo la niña fuente de dulzura, no fuese él un blanco agrio que aquella dulcifica con su presencia, y de ese modo suponer también que el sujeto se desplace golpeado o herido en algún sentido y que gracias a la «niña» reciba caricia y, por tanto, alivio?

\section{Temperatura, aroma, sabor}

La llama maravillosa de la niña es una llama que no quema. Llegamos a comprobar definitivamente que la flama que ilumina al observador lo toca sin dañarlo. Lo envuelve y penetra de un modo benéfico. Es una presencia bienhechora que tiene una extensión más bien difusa, pero suficiente para alumbrar y procurar apaciguamiento.

A la luminosidad, calidez, sonoridad suave y fresco aroma que proceden de la presencia llameante y humana se suman cualidades sensibles de tipo gustativo y de tipo táctil que poseen una baja intensidad similar. Lo gustativo que aparece en la calificación de la mirada femenina: «cálidos ojos de dulzura». Lo táctil, por su parte, que aparece en los «besos de amor matutino», contacto a partir del cual se inicia un seguro trayecto hacia un mundo maravilloso.

La expresión "cálidos ojos de dulzura» expone un sincretismo sensible que reúne lo táctil («cálido»), lo visual («ojos») y lo gustativo («dulzura»). La figura de la calidez compagina con la figura de la dulzura, por ser ambas propiedades de extensión medianamente concentradas y de intensidades débiles. Las dos, a su vez, conjugan con las figuras sensibles de la frescura aromática, la sonoridad de la voz infantil y melodiosa, y la dulzura que se caracteriza por sus intensidades débiles y sus consistencias livianas. El sintagma "besos de amor matutino» procura a su turno sensaciones de frescor y de luminosidad tenue, que aumentan la moderación de las intensidades y la liviandad de las presencias sensibles. Pero la moderación de las intensidades y la extensión difusa de las cualidades sensibles que la niña presenta tienen una tonalidad cuya valencia en fuerte, y que hacen posible su 
valorización positiva. De ese modo los tonos moderados ocupan en el universo semántico y tensivo del poema la posición de lo deleitable y placentero, respecto de los tonos fuertes que ocuparían la posición de lo desagradable y mortificante.

\section{Cuerpos móviles}

El recorrido de la niña en su acercamiento al observador tiene un itinerario perceptible que comienza con la aparición de la que se capta sólo el perfil débilmente refulgente; sigue con la aprehensión de los gestos humanos y del cuerpo llameante, que aflora nítido y ligeramente cálido; progresa con la percepción de la voz y del aroma, cualidades sensibles que penetran el cuerpo del observador y llegan a tocar su carne -lugar de la mismidad profunda-conmoviéndola. Avanza con la penetración dulce de la mirada y termina con la unión amorosa del beso, que ingresa en el cuerpo gracias a sus mezcladas cualidades sensibles de calidez, frescura y dulzura, que dejan huella en la piel, en las papilas y en la memoria. Una huella suave, que convoca el recuerdo del calor moderado que la presencia de la llama suave produce en la piel y en la carne.

Se trata de propiedades sensibles captadas por el observador en un horizonte de contrastes: la calidez, la frescura y la dulzura externas (exteroceptivas) se descubren sobre un fondo sensible interno en que aparecen las cualidades sensibles de la acidez, el calor interior y la humedad que experimenta el cuerpo propio en su interior (y que tienen un carácter interoceptivo). Puede así postularse que el sabor de la dulzura se opone y sucede a la acritud, la frescura al calor interno, la calidez del fuego a lo húmedo que atraviesa el cuerpo. De este modo aparece un escenario sensible en el cual vemos pasar al observador de un horizonte sensible en el que reinan la acidez, el calor interno y la humedad antes de su encuentro con la niña, a otro en el que reinan la calidez, la frescura y la dulzura después de ocurrido el contacto. $\mathrm{O}$ mejor dicho, tiene lugar un evento en el cual el hombre ácido, que sufre de calores internos y que se halla enfriado por la humedad, es invadido por las delicias de la dulzura, la suave calidez y la frescura.

Un cuadro de las oposiciones aquí planteadas es el siguiente: 
En este cuadro incluimos al deseo, que es pasión que emana de la presencia

femenina, y presente en los verbos insinuar y seducir, y que fluye de la presencia masculina, lo que deducimos de la atención, atracción y apego que surgen en el observador. La pasión del deseo es una disposición que se opondría no al temor sino a la afánisis, según Lacan, que es el cese completo de todo apetito sexual. Por deseo entendemos una disposición en el sentido que a esta categoría da Fontanille. La proyección imaginaria (fantasía en términos psicoanalíticos) de la aprehensión de un objeto atractivo, que toca el cuerpo imantándolo de un modo a la vez irresistible y contrariado. El cuerpo deseante aparece como una entidad sujeta a un objeto, determinado tanto por el querer como por el deber, al que por lo demás nunca llega a captar de modo perfecto. Sin profundizar en esta dirección únicamente hemos de señalar que el deseo femenino se caracteriza por una disposición irresistible a la atracción, mientras que el masculino por una disposición irresistible para ser atraído.

\section{Algunas conclusiones}

La significación surge de la correlación de dimensiones dependientes. De la articulación entre el plano de la expresión y el plano del contenido, de la dimensión de lo sensible (llamada en semiótica intensidad) con la dimensión de lo inteligible (llamada extensión o extensidad). Pero también la significación surge de la 
captación de las variaciones que tienen lugar en los procesos. La alteración de lo mismo (que lo convierte en otro), el cambio de grado de una temperatura, por ejemplo, o la diferencia de matiz percibida en un color, constituye la mutación y a la vez la partición más elemental de la que emerge el proceso significativo. A menudo tal cambio sobreviene, surge imprevisto debido a una aparición súbita y deslumbrante, que al desplegarse se va diluyendo y apagando. Pero tal aparición puede también surgir de un alumbramiento. El proceso por el cual se produce un ascenso, una iluminación paulatina y creciente, que al tiempo que intensifica la tonicidad de su presencia, la hace muy sensible, se desarrolla una concentración de su consistencia y cohesión material. «La niña de la lámpara azul» de José María Eguren es un texto en el que se ofrece esa iluminación. Es una luminiscencia que no sobreviene sino a la que un observador sensible va accediendo en la medida en que se va imponiendo sobre la oscuridad de un modo lento y progresivo, y que se homologa en primer lugar con una erótica (embotamiento / sensualidad), con una estética (asombro / fascinación), con una fiducia (incertidumbre / certidumbre), con una pragmática (rutina / magia), con una tópica (mundo propio / otro mundo) y hasta con una mítica (profano / sagrado). La principal presencia de «La niña de la lámpara azul» va tomando en el desarrollo del poema una condición exclusiva y excluyente, al tiempo que toda otra esfera que se sitúa fuera de su entorno inmediato se hace participativa, formada por las mezclas de lo oscuro o de lo diurno invariante.

\section{Notas}

' «La niña de la lámpara azul» ya fue motivo de un análisis semiótico desarrollado por Desiderio Blanco y Raúl Bueno hace veintiséis años. Cf. Blanco, Desiderio [y] Bueno, Raúl. Metodología del análisis semiótico. Lima: U. de Lima, 1980.

2 Greimas, A. J. De la imperfección. México: FCE, 1990.

3 Consultar al respecto el último libro de Eric Landowski Passions sans nom. Paris: PUF, 2004. Especialmente el capítulo I. 
4 Clepsidra es el reloj de agua, que mide el tiempo sobre la base de lo que tarda una cantidad de agua en pasar de un recipiente a otro, de iguales dimensiones, que está debajo. Por extensión, se ha llamado también clepsidra al reloj de arena.

5 Tournier, Alain. Vendredi Les Limbres du Pacifique. Paris: Gallimard, 1967. citado por A. J. Greimas. Op. Cit. P. 29.

6 Cf. Greimas, A. J. y Fontanille, Jacques. Semiótica de las pasiones. México: Siglo XXI editores, 1994.

7 Zilberberg, Claude. Semiótica tensiva. Traducción del francés: Desiderio Blanco. Lima: Fondo Editorial de la Universidad de Lima, 2007.

8 Más adelante explicaremos las razones por las cuales consideramos que la luz alumbrado es una expresión de lo rutinario, basándonos en Fontanille, Jacques. Semiotique du visible. Paris: PUF, 1995.

9 Fontanille, Jacques. Semiótica del discurso. Lima: Universidad de Lima y FCE, 2001. Fontanille, Jacques y Zilberberg, Claude. Tensión y significación. Lima: Universidad de Lima y FCE, 2004. Zilberberg, Claude, Semiótica tensiva. Lima: Fondo Editorial de la Universidad de Lima, 2007.

10 Estos análisis se fundan en esquemas y categorizaciones realizadas por Claude Silberberg en el libro que aquí citamos.

11 Marina, José Antonio y López Peras, Marisa. Diccionario de los sentimientos. Barcelona: Editorial Anagrama, 1999. pp. 118-136.

12 Permítasenos el siguiente apunte: el deseo en general es una sensación que tanto se experimenta en la piel como dentro del cuerpo y es una sensación móvil que se desplaza, entre otros movimientos, de la piel hacia el interior sensorio motriz del cuerpo y de ese centro hacia el exterior. La piel sensibilizada por el deseo se eriza y enrojece, aunque también puede palidecer. El hecho es que, sin querer agotar el análisis del deseo, es una sensación que se puede expresar en la piel a través de múltiples cualidades. El interior sensorio motriz igualmente puede expresar la sensación del deseo mediante diversas manifestaciones. Se la puede suponer formada por movimientos de dilatación y de contracción simultáneamente eufóricas y disfóricas, pues el deseo al tiempo que place displace. Por eso en el universo corporal del poema tanto en una como en otra posición somática la iluminación en medio de una noche cerrada produce en el observador impulsos de atracción hacia ella. El cuerpo que seguramente viene contraído y apretado, debe distenderse con la luz, desde las membranas hasta el interior carnal, y dirigirse hacia una distensión mayor. Y de aquí inferir que tal placentera distensión no sólo procede de la luz, sino también del calor que de ella emana. Un calor no muy intenso por cierto, porque no quema, pero envolvente y penetrante.

13 Cf. Greimas, A. J. En torno al sentido II. Madrid: Editorial Gredos, 1989.

14 Fontanille, Jacques. Soma et séma. Figures du corps. Paris: Maisonneuve \& Larose, 2004.

Fontanille, Jacques. Op. cit.

16 La dirección ascendente de un estado de ánimo es correspondiente y concomitante con la dirección decadente del estado de ánimo contrario, de la misma manera que un programa narrativo de adquisición es correspondiente en un sentido inverso por un programa narrativo de disjunción. En la semiótica tensiva imaginada por Zilberberg, sin embargo, los estados de ánimo forman una unidad partida en dos direcciones. En el poema que analizamos ocurre, no obstante, una separación afectiva, como si lo disfórico y lo eufórico siguieran carriles diferentes. 


\section{Referencias bibliográficas}

BLANCO, Desiderio y Bueno, Raúl (1980): Metodología del análisis semiótico. Universidad de Lima, Lima.

FONTANILLE, Jacques (1995): Semiotique du visible. PUF, Paris. (2001): Semiótica del discurso. Universidad de Lima y FCE, Lima.

(2004): Soma et sema. Figures du corps. Maisonneuve \& Larose, Paris.

Fontanille, Jacques y Zilberberg, Claude (2004): Tensión y significación. Universidad de Lima y FCE, Lima.

GREIMAS, A. J. (1989): En torno al sentido II. Editorial Gredos, Madrid. (1990): De la imperfección. FCE, México.

GREIMAS, A. J. y Fontanille, Jacques (1994): Semiótica de las pasiones. Siglo XXI editores, México.

LANDOWSKI, Eric (2004): Passions sans nom. PUF, Paris.

MARINA, José Antonio y López Peras, Marisa (1999): Diccionario de los sentimientos. Editorial Anagrama, Barcelona.

ZILBERBERG, Claude (1999): «Semiótica de la dulzura». Traducción: Desiderio Blanco. En Lienzo, revista de la Universidad de Lima. $\mathrm{N}^{\circ} 20$.

(2007): Semiótica tensiva. Traducción: Desiderio Blanco. Fondo editorial de la Universidad de Lima, Lima. 